\title{
Hemanjiyomu Nedeniyle Propranolol Tedavisi Verilen Çocuklarda Tek Lokalizasyon veya Çoklu Lokalizasyon ile Prognoz Arasındaki İlişkinin Değerlendirilmesi
}

\author{
Evaluation of the Relationship Between Single Localization or \\ Multiple Localization and Prognosis in Children with Hemangioma \\ Given Propranolol Treatment
}

Hüseyin ÖZLÜ1

\author{
'Gümüşhane Devlet Hastanesi Çocuk Sağlığı ve Hastalıkları Bölümü, Gümüşhane, Türkiye \\ ${ }^{2}$ Ankara Şehir Hastanesi, Çocuk Kardiyoloji Kliniği, Ankara, Türkiye \\ ${ }^{3}$ Ankara Şehir Hastanesi, Çocuk Onkoloji Kliniği, Ankara, Türkiye
}

\section{Öz}

Amaç: Infantil hemanjiyomlar çocukluk çağının en sık görülen vasküler tümörleridir. Kendiliğinden küçülme özelliği izlemde avantaj sağlasa da yerleşim yerine bağlı olarak oluşturduğu komplikasyonlar nedeni ile \%10-20 hastada tedavi gerekmektedir. Çalışmada propranolol tedavisi başlanan ve iç organ tutulumu açısından taranan hastalarda, propranolol tedavisinden fayda görme oranı ve tek veya çoklu tutulumun prognoza olan etkisinin belirlenmesi amaçlandı.

Gereç ve Yöntemler: Infantil hemanjiyom nedeniyle 2015-2018 tarihleri arasında merkezimize başvuran ve oral propranolol tedavisi başlanan 60 hastanın demografik özellikleriyle birlikte başvuru anındaki, izlem sırasındaki ve son kontroldeki hemanjiyom boyutları, tedavi endikasyonları, tedavi süreleri, tedavi yanıtları ve tedavi öncesi kardiyak değerlendirme sonuçları değerlendirildi.

Bulgular: Hastaların 37'si (\%61.7) kızdı, lezyonların ortanca fark edilme yașı 3 ay iken, tedavi bașlama ortanca yaşı 5 aydı. İzlem süresi ortalama 21 aydı ve propranonol tedavisinin ortalama 8 ay süre ile verildiği saptandı. En sık \%26.7 oranla baş yüz bölgesi yerleşimli hemanjiyom görüldü. Hemanjiyomlar en sık yüzeyel ve lokalize şekildeydi. Ortalama hemanjiyom büyüklüğü $12.3 \mathrm{~cm}^{2}$, ortanca $3.50 \mathrm{~cm}^{2}$ olarak saptandı. En küçük lezyon $0.25 \mathrm{~cm}^{2}$, en büyük lezyon 225 $\mathrm{cm}^{2}$ olarak saptandı. 43 hastada (\%71.6) lezyonlar tek sayıda iken, 17 hastada (\%28.3) iki ve üzerinde lezyon vardı. Çalışmamızda farklı lokalizasyonlarda en fazla üç lezyonu olan hastalar mevcuttu. Multifokal hemanjiyom izlenmedi. Komplikasyon görülme oranı \%33.3'tü ve kanama 12 hasta ile en sık görülen komplikasyon oldu. Tedaviye en sık ailenin kozmetik nedenli kaygısı (\%30) nedeniyle başlanmıştı. Tedavi yanıtlarına göre 15 hastada tedaviye yanıtsızlık veya minimal derecede regresyon (<\%25), 45 hastada ise \%25 üzerinde yanıt görüldü. Olguların hastanemizde rutin tedavi öncesi bakılan elektrokardiyografi ve risk faktörü durumunda bakılan ekokardiyografi sonuçları değerlendirildiği zaman hiçbir hastada propranolol tedavisi almasına engel durum oluşturacak patoloji saptanmadı.

Sonuç: Infantil hemanjiyomlar sıklıkla saçlı deri-boyun ve yüz bölgesi olmak üzere vücudun çeşitli lokalizasyonlarında görülebilmektedir. Çoklu tutulumun propranolol tedavisi etkinliği üzerine yaptığımız bu çalışma, hemanjiyomun tek lokalizasyon veya çoklu lokalizasyon tutulumunun tedavi yanıı üzerine etkisi olmadığını göstermiştir.

Anahtar Sözcükler: Çocukluk çağı, Infantil hemanjiyom, Prognoz, Propranolol, Vasküler anomaliler

(1)
Çıkar Çatışması / Conflict of Interest: Tüm yazarlar adına, ilgili yazar çıkar çatıșması olmadığını belirtir.

Etik Kurul Onayı / Ethics Committee Approval: Sağ|k Bilimleri Üniversitesi Ankara Çocuk Sağlı̆̆ı ve Hastallkları Hematoloji Onkoloji Eğtitim ve Araștırma Hastanes Klinik Araştırmalar Etik Kurulu'ndan 2018-191 numaralı protokol kodu ile onay alindl.

Yazarların katkısı / Contribution of the Authors: ÖZLÜ H: Araștırma ve/veya makalenin hipotezini veya fikrini olușturan, Sonuçlara ulașmak için planlama/ metodoloji belirleme, Hasta takibinde sorumluluk almak, ilgili biyolojik malzemelerin toplanması, veri yönetimi ve raporlama, deneylerin yürütülmesi, Sonuçların mantıksal olarak Yorumlanması ve sonuçlandırıması, Çalıșma için gerekli literatür taramasında sorumluluk almak, Çalıșmanın bütününün veya önemli bölümlerinin yazımında sorumluluk almak. ÇETiN ii: Araștırma ve/veya makalenin hipotezini veya fikrini olușturan, Araștırma/çalıșmanın sorumluluğunu üstlenmek, ilerlemenin yazımında sorumluluk almak. ÇETiN ii: Araştırma ve/veya makalenin hipotezini veya fikrini olușturan, Araştırma/çalışmanın sorumluluğunu üstlenmek, ilerlemenin
seyrini denetlemek, Sonuçların mantıksal olarak Yorumlanması ve sonuçlandırılması, Yazım ve dilbilgisi dışında bilimsel olarak gönderilmeden önce makaleyi gözden geçirme. ÖZYÖRÜK D: Araştırma ve/veya makalenin hipotezini veya fikrini oluşturan, Araştırma/çalışmanın sorumluluğunu üstlenmek, ilerlemenin seyrini denetlemek, Sonuçların mantıksal olarak Yorumlanması ve sonuçlandırıması, Yazım ve dilbilgisi dışında bilimsel olarak gönderilmeden önce makaleyi gözden geçirme

Atıf yazım şekli / How to cite : Özlü H, Çetin ii, Özyörük D. Hemanjiyomu Nedeniyle Propranolol Tedavisi Verilen Çocuklarda Tek Lokalizasyon veya Çoklu Lokalizasyon ile Prognoz Arasındaki Ilişsinin Değerlendirilmesi. Turkish J Pediatr Dis 2022;16:86-92. 


\section{ABSTRACT}

Objective: Infantile hemangiomas are the most common vascular tumors in childhood. Although spontaneous regression provides an advantage in clinical follow-up; treatment is required in \%10-20 of the patients due to complications it creates depending on the location. In the study, it was aimed to determine the rate of benefit from propranolol treatment and the effect of single or multiple involvement on prognosis in patients who were started on propranolol treatment and were screened for internal organ involvement.

Material and Methods: The demographic characteristics of 60 patients who were admitted to our center for infantile hemangioma between 2015 and 2018 and were started on oral propranolol therapy, along with the hemangioma size at the time of admission, during follow-up and at the last control , treatment indications , treatment durations, treatment responses and pre-treatment cardiac evaluation results were evaluated.

Results: Thirty-seven (61.7\%) of the patients were female, the median age of recognition of lesions was 3 months, and the median age of initiation of treatment was 5 months. The average follow-up period was 21 months and it was found that propranonol treatment was given for an average of 8 months. The most frequently \%26.7 compared head of localized facial hemangioma was observed. Hemangiomas were mostly superficial and localized. The mean hemangioma size was $12.3 \mathrm{~cm}^{2}$, and the median was $3.50 \mathrm{~cm}^{2}$. The smallest lesion was $0.25 \mathrm{~cm}^{2}$ and the largest lesion was $225 \mathrm{~cm}^{2}$. While 43 patients (\%71.6) had an odd number of lesions, 17 patients (\%28.3) had two or more lesions. In our study, there were patients with at most three lesions in different localizations. Multifocal hemangioma was not observed. Complication incidence rate was \%33.3 and bleeding was the most common complication with 12 patients. The most common treatment was started due to the cosmetic concern of the family (\%30). Response to treatment in 15 patients treated according to unresponsiveness or minimal regression $(<\% 25)$ and response was seen in 45 patients over \%25. When the electrocardiography results of the patients before routine treatment in our hospital and echocardiography results in the case of risk factors were evaluated, no pathology that would prevent the patients to receive propranolol treatment was found.

Conclusion: Infantile hemangiomas can be seen in various localizations of the body often in the scalp, neck and face. This study on the efficacy of propranolol treatment of multi-involvement showed that single localization or multiple localization involvement of the hemangioma had no effect on treatment response.

Key Words: Childhood, Infantile hemangioma, Prognosis, Propranolol, Vascular anomalies

\section{Giriş}

İnfantil hemanjiyomlar $(i H)$ çocukluk çağında en sık görülen görülen vasküler tümörler olup, gelişimsel olarak erken ve hızı proliferasyon fazını spontan ve yavaş involüsyon fazı izler. Sıkı|kla parlak kırmızı renkte yüzeyel lezyon şeklinde görülmesiyle birlikte bazen cildin dermis tabakasına ve iç organlara da yerleșebilen, oluşturduğu komplikasyonlar ve kalıcı deformite riski nedeniyle tedavi intiyacı olabilen iyi huylu kitlelerdir $(1,2)$.

Infantil hemanjiyomlar karakteristik bir gelişim gösterirler. Genellikle erken neonatal dönemde ortaya çıkarlar. 1-3 haftalık latent periyottan sonra tipik olarak büyümeye başlar. Büyüme hızı doğrusal değildir. Özellikle ilk 3 ay boyunca hızlı bir büyüme gösterir ve yaşamın 5-8.ayları arasında maksimum boyuta ulaşıllar. Yaklaşık \%80 oranında büyümesini bu dönemde tamamlamış olur. Segmental veya derin IH'u olan hastalarda yaşamın 9-12. ayına kadar ve nadiren 24. aya kadar büyüme devam edebilir. Genellikle kısmi stabilizasyon periyodunun ardından spontan küçülme başlar. Vakaların \%90'ında 4 yaşına kadar küçülme tamamlanır, daha derin hemanjiyomu olan hastalarda 7-8 yaşlarına kadar devam edebilir (3).

Anatomik lokalizasyonuna göre hemanjiyomlar; yüzeyel, derin, mikst ve kavernöz tip hemanjiyom olarak sınflandırılmaktadır (3). Anatomik dağlıma göre yapılan diğer sınıflamada ise hemanijyomlar lokal, segmental, multifokal ve belirsiz tip olarak isimlendirilir. Lokalize 'H'lar en sık görülen tip olup, oval veya yuvarlak şekilli küçük bir alanda yerleşim gösteren lezyonlardır. Segmental iH'lar ise daha geniş bir anatomik bölgeyi (lokalize IH'lardan en az 4 kat daha geniş bir alanı) veya gelişimsel bir birimi tutarlar. Multifokal infantil hemanjiyom en az beş tane hemanjiyom olması durumudur. (Eskiden adlandırılığı ismiyle benign/difüz neonatal hemangiomatozis). İndetermite hemanjiyom grubu ise diğer gruplara uymayan hemanjiyom tipidir. IH'lar en sık yüz (\%40) ve boyun (\%20) bölgesinde görülür. Ancak iç organlar da dahil olmak üzere vücudun her yerine lokalize olabilir (4).

Infantil hemanjiyomların büyük çoğunluğu 2-6. aylar arasında kendiliğinden küçülürler. Ancak \%10-20 oranında komplikasyon gelişen veya komplikasyon gelișme riski nedeniyle tedavi intiyacı doğan hasta mevcuttur. Ülserasyon, kanama, fonksiyon kaybı ve şekil bozukluğu sık görülen komplikasyonlardır (5).

Infantil hemanjiyom tanısı çoğunlukla öykü ve klinik ile konulabilmektedir. Ancak subkutan yerleşim gösteren ve deri yüzeyinde bulgu vermeyen derin IH'ların tanınması zor olabilir. Bu durumda ultrasonografi (USG), doppler USG, manyetik rezonans görüntüleme (MRG) tanıda yardımcı olabilmektedir (6).

Infantil hemanjiyomların çoğu bekle ve gör yaklaşımı ile tedavi intiyacı olmadan kendini sınırlar. Bazı hemanjiyom tiplerinin ise hemen tedavi edilmesi gerekir (7). Medikal tedavi hemanjiyom anatomik olarak riskli bölgelerdeyse (perioküler, havayolu ve anogenital bölge) veya hızlı büyüme göstermesi obstruksiyona, ülserasyona veya organ disfonksiyonuna neden olacaksa gereklidir (8).

Son on yılda IH'un patogenezi ve klinik seyri hakkında etkileyici ve temel değişiklikler olmasına rağmen, en belirgin değişiklikler tedavi standardında beta bloker tedaviye doğru tam bir kayma ile gerçekleşmiştir (9). Çalışmamızda hemanjiyom hastalarında yeni bir çığır açan propranolol tedavisinin çoklu lokalizasyon 
tutulumu olan hastalardaki prognostik değerinin belirlenmesi amaçlanmıştır.

\section{GEREÇ ve YÖNTEMLER}

Infantil hemanjiyom nedeniyle 2015-2018 tarihleri arasında merkezimize başvuran ve oral propranolol tedavisi bașlanan 60 hastanın demografik özellikleriyle birlikte başvuru anındaki, izlem sırasındaki ve son kontroldeki hemanjiyom boyutları, tedavi endikasyonları, tedavi süreleri, tedavi yanıtları ve tedavi öncesi kardiyak değerlendirme sonuçları değerlendirildi. Çalıșmaya alınan hasta kayıtlarına Sağlık Bilimleri Üniversitesi Ankara Çocuk Sağlığı ve Hastalıkları Hematoloji Onkoloji Sağlık Uygulama ve Araştırma Merkezi hasta veri sistemi SARUS Klinik Portal (EES-Entegre Enformasyon Sistemleri Eğitim ve Danışmanlık Tic. A.Ş.) üzerinden ulaşıldı. Sağlık Bilimleri Üniversitesi Ankara Çocuk Sağlığı ve Hastallıları Hematoloji Onkoloji Eğitim ve Araștırma Hastanesi Klinik Araștırmalar Etik Kurulu'ndan 2018-191 numaralı protokol kodu ile onay alındı.

Hastaların yaşı, cinsiyeti, ilk başvuru tarihi ve başvuru yakınması, fizik muayene bulguları, lezyonun anatomik lokalizasyonu, tipi, sayısı, başvuru anındaki, takip sırasındaki ve son kontroldeki hemanijiyom boyutları (fizik muayene, USG, MR), tedaviye bașlama yaşı, tedavi bașlama ve bitirme endikasyonları, tedavi süresi, tedavi bașlamadan önce ve tedavi sırasındaki kardiyak değerlendirme sonuçları, tansiyon değerleri, hastanın ek hastalı̆ı olup olmadığı ve ilaç etkileşimi açısından ek ilaç kullanımı kaydedildi.

\section{İstaktiksel analiz}

Araștırma verilerinin istatistiksel analizleri için Statistical Package for Social Sciences (SPSS), Windows için sürüm 25.0 (Statistical Package for the Social Sciences) (SPSS Inc. Chicago, USA) bilgisayar paket programı kullanılmıştır. Tanımlayıc ı istatistiklerden yararlanıldı. Veriler $n(\%)$ veya ortalama \pm standart sapma veya ortanca (IRQ) olarak özetlendi.

\section{BULGULAR}

Çalışmaya dahil edilen altmış olgunun 37'si (\%61.7) kız, 23'ü (\%38.3) erkekti. Ortalama olarak hastalara 9 ay civarı, ortanca 5 aylıkken tedavi başlandığı görüldü. Hasta grubumuzda en erken 2 aylıkken, en geç 81 aylıkken tedaviye başlanmıştı. Propranonol tedavisinin ortalama 8 ay süre ile verildiği saptandı. Olguların bașvuru sırasındaki ortalama yașı 7 ay, ortanca yaş 3 ay (en küçük 1 ay, en büyük 80 ay) olarak ve izlem süresi ortalama 21 ay olarak saptandı.

Morfolojik özelliğine göre sınıflandırıldı̆ı zaman 40 (\%66.6) hastada yüzeyel tip, 10 (\%16.6) hastada mikst tip, 5 (\%8.3) hastada derin tip ve 5 (\%8.3) hastada kavernöz tip hemanjiyom saptandı. Yüz, gövde ve perineal-gluteal bölgedeki lezyonların daha çok yüzeyel tipte (n:16) ve karaciğerdeki lezyonların çoğunlunun kavernöz tipte (n:5) olduğu görüldü. Hemanjiyom yerleşim yeri ile morfolojik özelliği arasında istatistiksel olarak anlamlı ilişki saptanmadı (p:0.464). Ayrıca hemanjiyomun tek veya çoklu olması ile morfolojik özellik arasında da ilişki saptanmadı (p:0.622).

Olguların 16 (\%26.7) 'sında hemanjiyom baş-yüz bölgesinde, 13 (\%21.7)'ünde baş-saçlı deri boyun bölgesinde, 5 (\%8.3)'inde gövde, 10 (\%16.7)'unda perineal-gluteal bölgede, 7 (\%11.7)'sinde karaciğer, 9 (\%15)'unda da ekstremite yerleșimliydi (Grafik-1).

Anatomik dağlıma göre hemanjiyom tiplerini Tablo l'de gösterildiği üzere değerlendirdiğimiz zaman 36 hastada (\%60) lokalize, 19 hastada (\%31.6) segmental ve 5 hastada (\%8.3) belirsiz tipte hemanjiyom izlendi. 5 ve üzeri sayıda hemanjiyomu olan hasta olmadı̆̆ı için multifokal hemanjiyom ise hiçbir hastada tanımlanamadı. Çalışmamızda lokalize tipte lezyonlar daha çok yüz (n:11), baş-boyun (n:7) ve perineal-gluteal (n:9) bölgede, segmental lezyonlar ise daha çok ekstremite (n:6), baș-boyun (n:5) ve yüzde (n:4) görüldü. Fakat lezyon yeri ile dağllıma göre hemanjiyom tipleri arasında istatiksel olarak anlamlı bir ilişki saptanmadı (p:0.570).

Çalışmamızda hemanjiyom boyutu iki dikey yüzey çapının esnek bir ölçüm bandı ile ölçülmesi ile elde edildi. Ölçülemeyecek lokalizasyonda olan lezyonlarda görüntüleme yöntemlerinden destek alındı. Çalışmamızdaki en küçük lezyon $0.25 \mathrm{~cm}^{2}$, en büyük lezyon $225 \mathrm{~cm}^{2}$ olarak saptandı. Ortalama hemanjiyom büyüklüğü 12.3 cm², ortanca hemanjiyom büyüklüğü $3.50 \mathrm{~cm}^{2}$ olarak saptandı. Ortalama ile ortanca arasındaki bu fark büyük hemanjiyomların ortalama büyüklüğü arttırması sonucunda oluşmuştur.

Hemanjiyomları büyüklüklerine göre sınılandırdığımızda 48 lezyon (\%57.8) $5 \mathrm{~cm}^{2}$ den küçük, 27 lezyon (\%32.5) $5-25 \mathrm{~cm}^{2}$ arasında ve 8 lezyon (\%9.7) 25 cm²'den büyüktü. Baş-boyun, yüz, karaciğer ve gluteal-perineal bölgedeki hemanjiyomların genellikle $5 \mathrm{~cm}^{2}$ 'den küçük boyutlu olduğu ve $25 \mathrm{~cm}^{2}$ den büyük hemanjiyomların genellikle ekstremite yerleșimli olduğu görüldü (Tablo II).

Hemanjiyomlar lezyon sayısına göre değerlendirildiğinde 26'sı kız ve 17'si erkek olmak üzere toplam 43 hastada (\%71.6) lezyonlar tek sayıda iken, 11 kız ve 6 erkek ile toplam 17 hastada (\%28.3) ise iki ve üzerinde lezyon vardı. Lokalize hemanjiyomların daha çok tek sayıda olduğu görüldü (p:0.016).

Olgularn hastanemizde rutin tedavi öncesi baklan elektrokardiyografi (EKG) ve risk faktörü durumunda baklan ekokardiyografi (EKO) sonuçlan değerlendirildiği zaman hiçbir hastada propranolol tedavisi almasına engel durum oluşturacak patoloji saptanmadı. Olguların 33'ünün EKO'sunda herhangi bir patoloji saptanmadı. Patoloji saptanan 20 olgunun 7'sinde PFO, 6'sinda ASD, 1 hastada VSD, 1 hastada MY, 1 hastada TY, 1 hastada MVP, 
Tablo I: Anatomik dağılıma göre hemanjiyom tipi ile lezyon yeri ilişkisi.

\begin{tabular}{l|c|c|c|c}
\hline & \multicolumn{3}{c}{ Lezyon Yeri } & \multicolumn{2}{c}{ Anatomik Dağılıma Göre Hemanjiyom Tipleri } \\
\cline { 2 - 5 } & Lokalize & Segmental & Belirsiz & Multifokal \\
\hline Yüz & 11 & 4 & 1 & 0 \\
Baș-boyun & 7 & 5 & 1 & 0 \\
Gövde & 3 & 2 & 0 & 0 \\
Ekstremite & 1 & 6 & 2 & 0 \\
Karaciğer & 5 & 1 & 1 & 0 \\
Perineal-gluteal bölge & 9 & 1 & 0 & 0 \\
Toplam (n,\%) & $36(\% 60)$ & $19(\% 31.6)$ & $5(\% 8.3)$ & 0 \\
\hline
\end{tabular}

Tablo II: Hemanjiyom büyüklük grupları ve yerlerine göre dağılımı.

\begin{tabular}{|c|c|c|c|c|}
\hline Lezyon Yeri & $\begin{array}{c}<5 \mathrm{~cm}^{2} \\
\mathrm{n}(\%)\end{array}$ & $\begin{array}{c}5-25 \mathrm{~cm}^{2} \\
\mathrm{n}(\%)\end{array}$ & $\begin{array}{c}>25 \mathrm{~cm}^{2} \\
\mathrm{n}(\%)\end{array}$ & $\begin{array}{c}\text { Toplam } \\
\text { n (\%) }\end{array}$ \\
\hline Yüz & $13(27.1)$ & 9 (33.3) & 0 & $22(26.5)$ \\
\hline Baş-boyun & $8(16.7)$ & $7(25.9)$ & $1(12.5)$ & 16 (19.3) \\
\hline Ekstremite & $5(10.4)$ & 1 (3.7) & $4(50)$ & 10 (12.0) \\
\hline Gövde & $1(2.1)$ & $4(14.8)$ & $2(25)$ & $7(8.4)$ \\
\hline Karaciğer & $13(27.1)$ & $3(11.1)$ & 0 & 16 (19.3) \\
\hline Perineal-gluteal bölge & $8(16.7)$ & $3(11.1)$ & $1(12.5)$ & $12(14.5)$ \\
\hline Toplam & 48 (100) & $27(100)$ & $8(100)$ & 83 (100) \\
\hline
\end{tabular}

1 hastada PS (hafif derece), 1 hastada PDA ve 1 hastada ise LV' de hafif dilatasyon saptandı. 7 hastada ise EKO yapılmamıştı. EKG'de patolojik bulgu saptanan olgu olmadı.

Tedavi yanıtları, lezyon boyutlarının tedavi öncesi ve sonrasındaki boyutları karșilaștıılarak hemanjiyomun klinik yanıtına göre lezyonda küçülme ve yanıtsı olmak üzere 2 ana grupta değerlendirildi. Lezyonda küçülme durumu ise boyutun küçülme yüzdesine göre 3 grupta değerlendirildi. \%75 ve üzeri küçülmeler mükemmel derecede regresyon, \%51-74 oranında küçülmeler iyi derecede regresyon, \%2650 oranında küçülmeler orta derecede regresyon ve \%25 ve altındaki küçülmeler yanıtsız veya minimal regresyon olarak tanımlandı. Çalışmamızda 22 hastada mükemmel derecede regresyon (boyutta küçülme oranı\% \%75) mevcuttu. Hastaların 11 'inde iyi derecede regresyon (boyutta küçülme oranı \%5074), 12'sinde orta derecede regresyon (boyutta küçülme oranı \%25-49), 15 hastada ise minimal derecede regresyon veya tedaviye yanıtsızık (boyutta küçülme oranı <\%25) görüldü (Grafik-2). Tedavi yanılları ile lezyon sayısı, lezyon yeri veya tedavi başlama yaşı ( $<6$ ay ve $>6$ ay) arasında istatistiksel anlamda ilişki saptanmadı (sırasıyla p:0.343, p:0,404, p:0.315). Mükemmel derece regresyonun (> \%75 küçülme) $5 \mathrm{~cm}^{2 \prime}$ den küçük lezyonlarda daha fazla görüldüğü saptandı (p:0.025).

Tedavi 33 hastada (\%55) küçülme olması, 8 hastada (\%13.3) iyileșme olması ve 15 hastada (\%25) yanitsızık nedeni ile sonlandııımıştı. 2 hastada bronşiolit (\%3.3) ve 2 hastada (\%3.3) huzursuzluk șikayetleri olması üzerine tedaviye ara verilmiș ve takiplerinde hemanjiyom boyutlarında spontan küçülme olması üzerine hastanın tedavilerine devam edilmemiști.

\section{TARTIŞMA}

İnfantil hemanjiyomlardaki kız üstünlüğü literatürdeki birçok yayında mevcuttur. Şen ve ark. (10) tarafindan retrospektif olarak yapılan 50 olgulu bir çalışmada cinsiyet oranları \%64 kIz ve \%36 erkek olarak sonuçlanmıș. Chiller KG ve ark. (11) yaptıkları büyük bir çalışmada da \%79 kız ve \%21 erkek olarak bulunmuştur. Bizim çalışmamızda da kız-erkek oranı literatüre benzer şekilde kız üstünlüğü (\%61.7) mevcuttu.

Infantil hemanjiyomlar, sıklıkla yüz-saçlı deri-boyun bölgelerinde görülür. Haggström ve ark. (2) tarafından bin elli sekiz infantil hemanjiyom hastasının prospektif olarak değerlendirildiği büyük bir çalıșmada hastaların \%41.2'sinde hemanjiyomun yüz bölgesinde, \%21'i saçlı deri-boyun bölgesinde, \%23.3'ü gövdede, \%18.4'ü ekstremite ve \%6.1'i perineal bölgede izlenmiş. Benzer şekilde birçok farklı çalışmada da baş-boyun yerleșim üstünlüğünün mevcut olduğu görülmüştür (12-14). Bizim çalışmamızda da diğer çalişmalara benzer șekilde yüz (\%26.7) ve baş-saçlı deri boyun bölgesinde (\%21.7) hemanjiyom görülme oranı daha yüksekti.

Hastane başvuruları genellikle hızlı büyümenin olduğu dönemde ilk 3 ay içerinde gerçekleşir. Ülkemizde yapılan yüzonaltı olgunun yer aldığı bir çalışmada hemanjiyomların 1. ayda fark edilme oranı \%84, 2-6 ay arasında fark edilme oranı \%11 bulunmuştur (13). Çalıșmamızda sıfir-bir ay arasında 6 hasta (\%10), bir-üç ay arası 28 hasta (\%46.7), üç-altı ay arasında 18 hasta (\%30), altıdokuz ay arasında 2 hasta (\%3.3), dokuz ay ve üstünde 6 hasta 


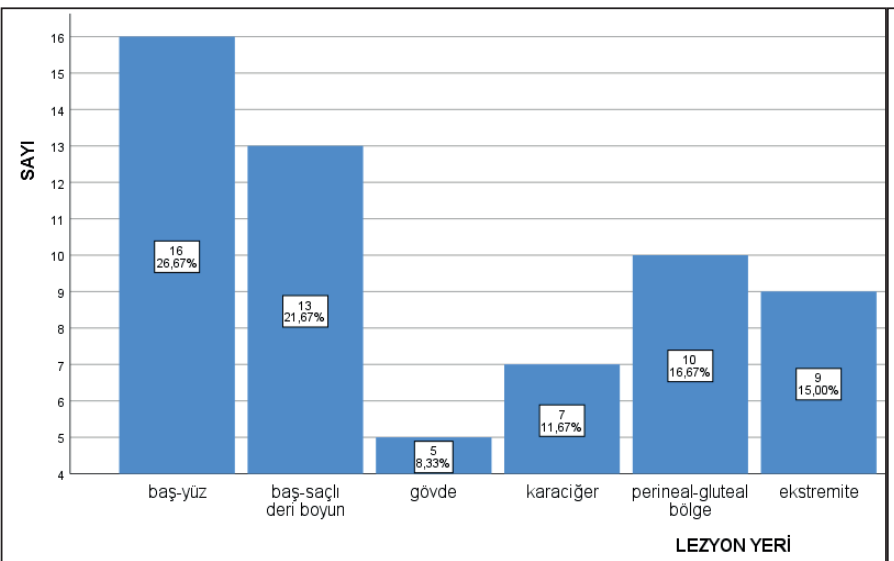

Grafik 1: Hemanjiyomların yerleşim yerlerine göre dağılımı.

(\%10) mevcuttu. Hastaların yarısından fazlası ilk üç ay içerisinde tanı almıştı.

Hemanjiyomların büyük çoğunluğu kendiliğinden geriler. Ancak komplikasyon varlığı veya gelişebilecek komplikasyonlar nedeni ile tedavi intiyacı olabilmektedir (15). Çalıșmamızdaki hastaların tedavi başlama endikasyonları incelendiğinde; 18 hastada (\%30) ailenin kozmetik nedenli kaygısı, 11 hastada (\%18.3) yaygın dağııım sonucu kalıcı șekil bozukluğu riski nedeniyle, 10 hastada (\%16.6) kanama olması ve 4 hastada (\%6.6) travmaya sekonder kanama riski yüksek olan bölgelerde yerleşmiş olması, 9 hastada (\%15) hızlı büyüme olması, 3 hastada (\%5) hemanjiyomun enfekte olması, 3 hastada (\%5) solunum sıkıntısı yapması, 1 hastada (\%1.6) pitozis ve 1 hastada (\%1.6) beslenme güçlüğü olması nedeniyle başlanmıştı.

Infantil hemanjiyomlar sıklıkla tek lezyon şeklinde görülürken segmental ve çoklu hemanjiyomlar 'PHACES' sendromu ve 'SACRAL/PELVIS' sendromu açısından, multifokal hemanjiyomlar da sistemik tutulum açısından değerlendirilmelidir (16). Sekiz Avrupa ülkesinde yapılan 1097 çocuğun değerlendirildiği bir çalıșmada hemanjiyomların \%92.8'inin lokalize olduğu diğerlerinin segmental (\%5.5), multifokal (\%0.8) veya belirsiz (\%0.9) karakterde olduğu saptanmış (17). Çalışmamızda 36 hastada (\%60) lokalize, 19 hastada (\%31.6) segmental ve 5 hastada (\%8.4) belirsiz tip hemanjiyom izlendi. En fazla üç adet hemanjiyomu olan hastalar mevcuttu bu nedenle multifokal hemanjiyom izlenmedi. Lezyon yeri ile anatomik dağılıma göre hemanjiyom tipleri arasında istatiksel olarak anlamlı bir ilişki saptanmadı (p:0.570).

Horii ve ark. (18) tarafından yapılan bir çalışmada, bir ile dört arasında lezyonu olan hastalara yapılan abdominal USG'de karaciğer hemanjiyomu saptanmamıştı. Beș ve üzeri kütanöz IH'u olan yüz elli bir hastanın yirmi dördünde (\%16) ise soliter veya çoklu karaciğer hemanjiyomu saptanmıştı. Çalışmamızda tarama amaçlı yaklaşık olarak tüm hastalarda ultrasonografik görüntüleme yapıldl. (Abdomen= n:13, abdomen+yüzeyel= n:15, abdomen + transfontanel= n:17, abdomen+ yüzeyel+ transfontanel= n:14). Bir hastada tedavi

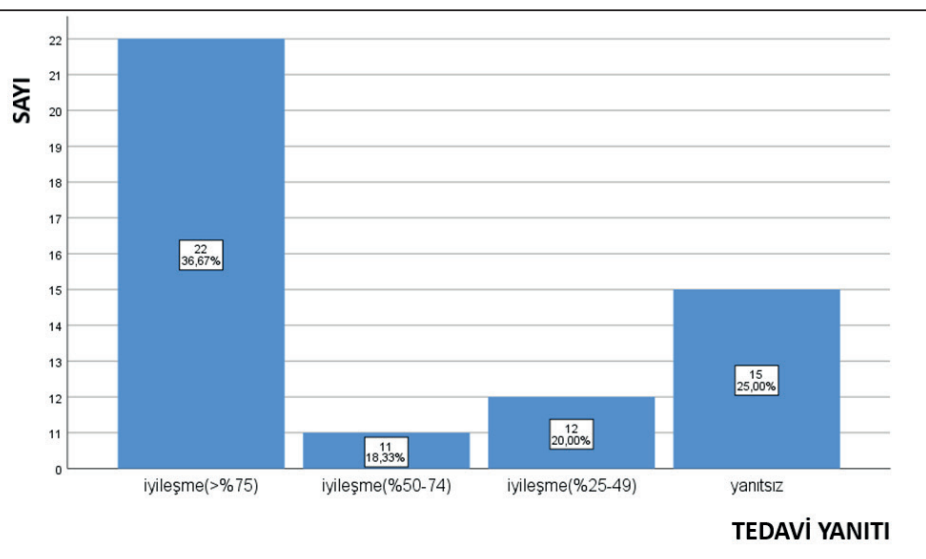

Grafik 2: Tedavi yanıtlarının dağııımı.

yanıtının hızlı olması nedeni ile tarama yapılmadı. Bu taramalar sonucu 7 hastada karaciğerde hemanjiyom saptandı. Karaciğerdeki hemanjiyomların en büyüğü $4 \mathrm{~cm}^{2}$ boyutundaydı. Tedavi ile hemanjiyomların tamamı iyilești veya takiplerinde boyutu küçüldü. Lezyonun lokalizasyonu sağlamlaştırmak, komplikasyonlar ve PHACES, LUMBAR/SAKRAL sendromları açısından değerlendirmek için 9 hasta kranial MR ve 4 hasta da ekstremite MR ile tetkik edilmiști.

Çalışmamızda hemanjiyomlar lezyon sayısına göre değerlendirildiğinde 43 hastada (\%71.6) lezyonlar tek sayıda iken, 17 hastada (\%28.3) ise iki ve üzerinde lezyon vardı. Denoyelle ve ark. (19) \%80 ile tek lezyon üstünlüğü bildirmişlerdir. Haktanır ve ark. (20) da benzer şekilde rapor etmişlerdir.

Boyut, yerleşim yeri ve hemanjiyom alt tipi; komplikasyonları ve/veya tedaviye intiyacı öngören ana faktörlerdir (2). Haggström'ün çalışmasında ülserasyon 168 hasta (\%16) ile en sık görülen komplikasyon olmuş. Daha az oranda görme tehdidi 59 (\%5.6), hava yolu obstruksiyonu 15 (\%1.4), işitme kanal tıkanıklı̆ı $6(\% 0.6)$ ve kalp yetmezliği $4(\% 0.4)$ hastada görülmüş. Karaciğerde hemanjiyom ise 10 hastada izlenmiş (2). Çalışmamızda ise literatürden farklı olarak kanama 12 hasta ile en sık görülen komplikasyon oldu. Ayrıca 3 hastada solunum sıkıntısı, 3 hastada ülserasyon, 1 hastada enfeksiyon ve 1 hastada pitoz izlendi.

IH'lu hastaların takibinde en büyük zorluk, hangi hastaların komplikasyonlar için yüksek risk altında olduğunu ve sistemik tedavi intiyacı olduğunu saptamaktır. Medikal tedavi kişiselleştirilmeli ve oral propranolol ile tedavi komplikasyon veya olası komplikasyon durumlarında bașlanmalıdır. IH için propranolol tedavisine başlamadan önce, propranolol kullanımına bağıı olası riskler için tarama yapıımalıdır. Öyküde önemli noktalar; beslenme azlığı, dispne, taşipne, hırıltılı, kardiyak üfürüm veya ailede kalp bloğu, aritmi öyküsü olmasıdır. Muayene kalp hızı, tansiyon ve kardiyak/pulmoner değerlendirmeyi içermelidir. Göreceli kontrendikasyonlar kardiyojenik şok, sinüs bradikardisi, hipotansiyon, 1.derece blok dışındaki bloklar, kalp yetmezliği ve astım-bronşittir. Yapısal ve işlevsel kalp hastalığı, 
komplike olmayan iH ile ilişkilendirilmemiştir, anormal klinik bulguların yokluğunda propranololün başlamasından önce rutin bir tarama aracı olarak ekokardiyografi gerekli değildir (21).

Çalışmamızda da rutin olarak tedavi öncesi EKG ve risk faktörü olması durumunda EKO ile hastalarımız değerlendirildi. Her hastadaEKG ile birliktetansiyon ölçümü deyapıldı. Hiçbirhastada tedaviye engel olacak EKO veya EKG bulgusu saptanmadı. Takip sırasında ve tedavi öncesinde bakılan tansiyon ölçümleri yaşları için normal sınılar içerisindeydi. Benzer sonuçlar Frongia ve ark. (22) tarafınca da rapor edilmiştir.

Çalışmamızda tedavi yanıtı olarak 22 hastada mükemmel derecede regresyon saptandı. Hastaların 11 'inde iyi derecede regresyon, 12'sinde orta derecede regresyon, 15 hastada ise minimal derecede regresyon veya tedaviye yanıtsılık saptandı. Benzer bir gruplama Turhan ve ark. (15) tarafindan 34 hasta ile yapılmışıı. 30 hastada mükemmel derecede regresyon, 3 hastada iyi derecede regresyon, 1 hastada orta dereceli regresyon görülmüş ve yanitsızlık veya minimal regresyon görülmemiştir.

Propranolol, müdahele gerektiren IH'larda güvenli ve etkili bir tedavidir. Propranolol tedavisi lezyon gerileme oranına göre uygun bir zamanda sonlandırımalıdır. İdeal sonlandırıma zamanı tamamen regresyonun sağlandığı durumda gerçekleștirilmelidir. Genellikle parsiyel regresyon görüldüğü için tedaviler daha uzun süreli tutulmalıdır. Propranolol; 12 aydan büyük çocuklarda ve 3 aydan uzun süredir maksimum küçülme elde edildiğinde, belirgin bir lezyon kalmadığında, tedaviye yanıt alınamadı̆̆ı durumlarda veya tedavi ile ilgili komplikasyon gelişmesi durumunda sonlandırımalıdır (12).

Birçok yapılan çalısmada propranolol dozu 2-3 mg/kg/gün arasında değişmektedir ve ortalama 6 aylık tedavi sonrası tam ve tama yakın tedavi yanıtı görülme oranı \%60 civarındadır (17). Tedavi dozu ve süresi ile ilgili tam bir görüş birliği oluşmamıştır. Değişik çalışmalarda tedavi dozu ve süresi farkllık göstermekte ve bu da tedavi yanıt oranlarını etkilemektedir (23). Şanlıurfa'da Özyörük ve ark. (24) tarafinca yapılan retrospektif bir çalışmada da altmış hemanjiyomlu hasta incelenmiş; hastaların \%23'üne $(n=14)$ propranolol tedavisi yaklaşık 6 ay süre ile uygulanmış ve olumlu sonuçlar elde edilmiştir. Çalışmamızda 0-6 ay tedavi alan 23 hasta (\%38.3), 6 ay-1 yıl tedavi alan 28 hasta (\%46.6), 1 yıldan uzun tedavi alan 9 hasta (\%15) mevcuttu. Hastalarımıza uygulanan tedavi sonuçları olumlu olmakla birlikte tedavi süresi ile tedaviden fayda görme oranları arasında istatistiksel açıdan anlamlı bir ilişki gösterilemedi.

Sonuç olarak yayınlarda hemanjiyomların benign yapısını vurgulamış olmasına rağmen skar bırakması ve şekil bozukluğunun hayatı tehdit etmese bile hayat kalitesini değiştirebilecek kozmetik sorunlar olușturma riski nedeni ile önemi giderek artmaktadır. Bu potansiyel yüz hemanjiyomlarında en yüksektir. İnternet üzerinden yayılan bilgiler, ailelerin iz kalması riski konusunda farkındalıklarını büyük ölçüde arııımıştır ve iz bırakma olasılığı düşük olan hemanjiyomlarda bile aşırı endişe ile sonuçlanabilmektedir. Hemanjiyomlar özellikle yaşamın ilk birkaç haftasında hızla çoğaldığı için, kalıcı yara izi de dâhil olmak üzere komplikasyonları önlemek amacıyla yüksek riskli hemanjiyomlarda tedavi başlamak gerekebilir. Bu çalışmada, tedavi başlanan durumlarda propranolol tedavisinin yanitı üzerine etkili olabilecek birçok faktörün (cinsiyet, boyut, lokalizasyon, sayı) etkinliğinin araştıııması amaçlanmışıı.

Son yıllarda IH'un patogenezi ve klinik seyri hakkında etkileyici ve temel yeni keşifler olmasına rağmen, en belirgin değişiklik tedavide beta bloker tedaviye doğru tam bir kayma ile gerçekleşmiştir. Oral kortikosteroidler yerine daha güvenli ve daha iyi tolere edilen bir ilaç olarak kabul edilen propranolol tercih edilmeye başlanmıștır. Bu son değişimin uzun vadeli etkileri henüz tam olarak net değildir. Biz de çalışmamızda hemanjiyom hastalarında yeni bir çı̆̆ır açan propranolol tedavisinin çoklu lokalizasyon tutulumu olan hastalardaki prognostik değerini belirlemeyi amaçladık.

\section{KAYNAKLAR}

1. Léauté-Labréze C, Hoeger P, Mazereeuw-Hautier J. A Randomized controlled trial of oral propranolol in infantile hemangioma. J Vasc Surg 2015;62:518-9.

2. Haggstrom AN, Drolet BA, Baselga E, Chamlin SL, Garzon MC, Horii KA, et al. Prospective study of infantile hemangiomas: clinical characteristics predicting complications and treatment. Pediatrics 2006;118:882-7.

3. Léauté-Labrèze C, Harper Jl, Hoeger PH. Infantile hemangioma. Lancet 2017;390:85-94.

4. Chiller KG, Passaro D, Frieden IJ. Hemangiomas of infancy: clinical characteristics, morphologic subtypes, and their relationship to race, ethnicity, and sex. Arch Dermatol 2002;138:1567-76.

5. Hoeger PH, Harper JI, Baselga E, Bonnet D, Boon LM, Atti MCD, et al. Treatment of infantile haemangiomas: recommendations of a European expert group. Eur J Pediatr 2015;174:855-65.

6. Menapace D, Mitkov M, Towbin R, Hogeling M. The changing face of complicated infantile hemangioma treatment. Pediatr Radiol 2016;46:1494-506.

7. Bota M, Popa G, Blag C, Tataru A. Infantile hemangioma: a brief review. Clujul Med 2015;88:23.

8. Grzesik P, Wu JK. Current perspectives on the optimal management of infantile hemangioma. Pediatr Heal Med Ther 2017;8:107-16.

9. Püttgen KB. Diagnosis and management of infantile hemangiomas. Pediatr Clin North Am 2014;61:383-402.

10. Zeynep Ş, Özakpınar HR, Görkem S, Özdemir OM, Ersoy A. Kutanöz vasküler lezyonlarda klinik yaklaşımlarımız. Ankara Üniversitesi Tıp Fakültesi Mecmuası 2002;55:193-204.

11. Chiller KG, Passaro D, Frieden IJ. Hemangiomas of infancy: clinical characteristics, morphologic subtypes, and their relationship to race, ethnicity, and sex. Arch Dermatol 2002;138:1567-76.

12. Chang L, Gu Y, Yu Z, Ying H, Qiu Y, Ma G, et al. When to stop propranolol for infantile hemangioma. Nat Publ Gr 2017;7:43292.

13. Akyüz C, Yariş N, Kutluk MT, Büyükpamukçu M. Benign vascular tumors and vascular malformations in childhood: a retrospective analysis of 1127 cases. Turk J Pediatr 1997;39:435-45. 
14. Garzon MC, Drolet BA, Baselga E, Chamlin SL, Haggstrom AN, Horii K, et al. Comparison of infantile hemangiomas in preterm and term infants: a prospective study. Arch Dermatol 2008;144:12312.

15. Turhan AB, Bör Ö, Özdemir ZC. Treatment with propranolol for infantile hemangiomas: single-center experience. J Cosmet Dermatol 2016;15:296-302.

16. Uda K, Mph YO, Matsushima T, Sadahira C, Kono T, Hataya H. Multifocal infantile hemangioma. J Pediatr 2019;210:238-238.e1.

17. Wedgeworth E, Glover M, Irvine AD, Neri I, Baselga E, Clayton TH, et al. Propranolol in the treatment of infantile haemangioma: lessons from the European propranolol in the treatment of complicated haemangiomas. Br J Dermatol 2016;174:594-601.

18. Baselga E, Chamlin SL, Haggstrom AN, Holland KE, Mancini AJ, Mccuaig CC, et al. Prospective study of the frequency of hepatic hemangiomas in infants with multiple cutaneous infantile hemangiomas. Pediatr Dermatol 2011;28:245-53.

19. Denoyelle F, Leboulanger N, Enjolras O, Harris R, Roger G, Garabedian E-N. Role of propranolol in the therapeutic strategy of infantile laryngotracheal hemangioma. Int J Pediatr Otorhinolaryngol 2009;73:1168-72.

20. Turhan-Haktanır N, Haktanır A, Ayçiçek A. Hemanjiyom ve vasküler malformasyonların isimlendirme ve sınılaması. Cerrahi Sanatlar Derg 2008;1:1-11.

21. Drolet BA, Frommelt PC, Chamlin SL, Haggstrom A, Nancy $M$, Chiu YE, et al. Initiation and use of propranolol for infantile hemangioma: report of a consensus conference abstract. Pediatrics 2013;131:140.

22. Frongia G, Byeon JO, Arnold R, Mehrabi A, Günther P. Cardiac diagnostics before oral propranolol therapy in infantile hemangioma: retrospective evaluation of 234 infants. World $\mathrm{J}$ Pediatr 2018;14:254-8.

23. Marqueling AL, Oza V, Frieden IJ, Puttgen KB. Propranolol and infantile hemangiomas four years later: a systematic review. Pediatr Dermatol 2013;30:182-91.

24. Özyörük D, Zengin E. Propranolol treatment of complicated hemangiomas. Indian J Pediatr 2014;81:368-7. 